\title{
Grupo de Trabalho Populações (In)Visibilizadas e Diversidades: Comunidade de Práticas Reafirmando Princípios da Abem
}

\section{(In)Visible Populations and Diversities Working Group: Community of Practices Reaffirming the Principles of the Abem}

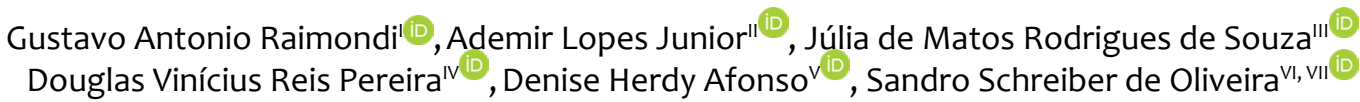

\section{RESUMO}

Introdução: A atual pandemia da Sars-CoV-2 (Covid-19) deixou ainda mais evidentes a desigualdade social e o impacto dos determinantes sociais nos indicadores de saúde. Por conta disso, os profissionais de saúde, para cuidar das pessoas e populações, devem desenvolver ações que promovam a equidade, papel que também cabe às instituições de ensino e saúde. As Diretrizes Curriculares Nacionais para os Cursos de Graduação em Medicina trazem em seu artigo $3^{\circ}$ que a formação do(a) graduando(a) deverá ocorrer com "responsabilidade social e compromisso com a defesa da cidadania".

Relato de Experiência: Este relato mostra como o debate da determinação social do processo de saúde e doença vem ocorrendo ao longo dos eventos nacionais de educação médica, especificamente nos Congressos Brasileiros de Educação Médica (Cobem), e como isso resultou na construção coletiva e colaborativa do grupo de trabalho Populações (In)Visibilizadas e Diversidades da Abem (GT-PIVD).

Discussão: Os Cobems têm ampliado as oportunidades para debates sobre determinantes sociais por meio de atividades relacionadas às questões LGBTI+, racial, da mulher e indígena. O GT-PIVD, criado em 2019, reúne um coletivo de educandos(as) e educadores(as) com o objetivo de promover esse debate na formação médica e nos eventos da Abem, além de ser uma comunidade de trocas de experiências sobre as populações (in)visibilizadas e diversidades.

Conclusão: Algumas iniciativas, como a "Carta de Porto Alegre", sobre equidade de gênero e diversidade sexual, e a criação do GT-PIVD, são produtos dos Cobem. O GT-PIVD, por meio de sua comunidade de práticas virtuais, tem se tornando um espaço importante de trocas de experiências entre educandos(as) e educadores(as) sobre racismo, sexismo, LGBTIfobia e outras violências, inclusive durante a pandemia da Covid-19.

Palavras-chave: Determinantes Sociais da Saúde; Grupos Minoritários; Educação Médica; Responsabilidade Social.

\begin{abstract}
Introduction: The current SARS-COV 2 pandemic (Covid-19) has made social inequality and the impact of social determinants on health indicators even more explicit. It is evident that health professionals, as well as educational and health institutions, must develop actions to promote equity in order to care for people and populations. The National Curricular Guidelines for Undergraduate Courses in Medicine bring in their third article that the training of the undergraduate student must occur with "social responsibility and commitment to promote citizenship".

Experience Report: This report presents how the debate on the social determination of the health and disease process has been taking place throughout the national Medical Education events, specifically in the Brazilian Medical Education Congress ("Cobem"), and how this resulted in the collective and collaborative initiative of the (In)Visible Populations and Diversities of the ABEM Working Group ("GT-PIVD").

Discussion: The "Cobems" have expanded opportunities for debates on social determinants through activities related to LGBTI+, race, women and indigenous issues. The "GT-PIVD", created in 2019, gathers students and educators with the aim of promoting this debate in medical settings and at ABEM events, constituting a community for exchanging experiences about (in)visible populations and diversities.

Conclusion: Some initiatives, such as the Porto Alegre Letter, on gender equality and sexual diversity, and the creation of the GT - PIVD, are products of the "COBEMs". The GT-PIVD, through its community of virtual practices, has become an important space for exchanging experiences between students and educators on racism, sexism, LGBTIphobia and other violence, including during the COVID-19 pandemic.
\end{abstract}

Keywords: Social Determinants of Health; Minority Groups; Medical Education; Social Responsibility.

'Universidade Federal de Uberlândia, Uberlândia, Minas Gerais, Brasil.

"Universidade de São Paulo, São Paulo, São Paulo, Brasil.

"'Universidade Federal dos Vales do Jequitinhonha e Mucuri, Teófilo Otoni, Minas Gerais, Brasil.

"Vaculdade Ciências Médicas de Minas Gerais, Belo Horizonte, Minas Gerais, Brasil.

'Universidade do Estado do Rio de Janeiro, Rio de Janeiro, Rio de Janeiro, Brasil.

v'Universidade Católica de Pelotas, Pelotas, Rio Grande do Sul, Brasil.

VIIUniversidade Federal do Rio Grande, Rio Grande, Rio Grande do Sul, Brasil.

Correspondência:

Gustavo Antonio Raimondi.

Universidade Federal de Uberlândia, Avenida Pará, 1720, bloco 2U, sala 8, campus Umuarama, Uberlândia, MG, Brasil. CEP: $38400-902$.

E-mail: gustavo.raimondi@gmail.com

Recebido em 11/08/20; Aceito em 28/08/20. 


\section{INTRODUÇÃO}

As Diretrizes Curriculares Nacionais para os Cursos de Graduação em Medicina (DCN) trazem em seu artigo $3^{\circ}$ que a formação do(a) graduando(a) deverá ocorrer com "responsabilidade social e compromisso com a defesa da cidadania". Associado a isso, a formação médica deverá considerar a determinação social do processo de saúde e doença (DSPSD) ${ }^{1}$

De acordo com o Consenso Global de Responsabilidade Social das Escolas Médicas ${ }^{2}$ e com a definição de responsabilidade social da Organização Mundial da Saúde $(\mathrm{OMS})^{3}$, compreende-se a importância de a educação, a pesquisa e os serviços à população responderem às demandas prioritárias de saúde de uma comunidade, região ou nação. Essas demandas devem ser pactuadas de forma dialógica com a população, os governos e as demais instituições sociais.

Ademais, a cidadania pressupõe a garantia do direito do acesso universal à saúde, um dos valores prioritários de um Estado democrático ${ }^{4}$. Em nosso contexto, o Sistema Único de Saúde (SUS) configura-se como a estratégia político-administrativa e sanitária de garantia desse direito ${ }^{5}$ e apresenta-se como um dos responsáveis por orientar a formação em saúde de graduandos(as) dos cursos de saúde. Isso ocorre para que consigamos, ainda que teoricamente, promover a responsabilidade social.

Atrelada a esse debate, a perspectiva da DSPSD amplia a responsabilidade social das escolas médicas ao explicitar que saúde consiste na "possibilidade de objetivação em cada indivíduo do grau de humanidade que a humanidade produziu" (p. 962) e que tais possibilidades dependem do desenvolvimento das forças produtivas, além das relações de produção estabelecidas ${ }^{6}$. Assim, observa-se que a formação médica, proposta pelas $\mathrm{DCN}^{1}$, deve ser fundamentada para além do componente biológico e técnico, que muitas vezes é fragmentado.

A pandemia da síndrome respiratória aguda grave coronavírus 2 (severe acute respiratory syndrome cronoravirus 2 - Sars-CoV-2) - coronavirus disease 2019 (Covid-19) exigiu um alinhamento das práticas educacionais com 0 momento sanitário/epidemiológico 7 . Ao longo da vivência dessa pandemia, a DSPSD explicitou a necessidade de refletirmos sobre como o cuidado e a formação em saúde têm considerado a responsabilidade social. Nesse sentido, o presente relato de experiência mostra como o debate da DSPSD vem ocorrendo ao longo dos eventos nacionais de educação médica, especificamente os Congressos Brasileiros de Educação Médica (Cobem) - que foram avaliados a partir dos seus sites eletrônicos presentes na página da Associação Brasileira de Educação Médica (Abem), - e como isso resultou na construção coletiva e colaborativa de um grupo de trabalho dedicado a essa temática.

\section{OS EVENTOS NACIONAIS EM EDUCAÇÃO MÉDICA}

No ano de $2015,053^{\circ}$ Cobem, realizado no Rio de Janeiro, apresentou como tema central "Educação médica e cuidados na saúde: uma rede em movimento". Quando se adentrava no local do evento, observava-se uma grande parede recoberta com papel Kraft. Nesse papel, havia um convite para que as mulheres relatassem situações de violência vivenciadas ao longo do seu processo formativo. Após alguns minutos, os primeiros relatos. Após algumas horas, poucos espaços vazios. Com a visceralidade da experiência vivida, quem por ali passava e dedicava um tempo para a leitura e reflexão sentia no próprio corpo como as questões de gênero e sexualidade, de raça e etnicidade, de classe social, entre outros, permeavam os espaços educacionais e reproduziam a violência. Havia nas escolas médicas, nos espaços de convivência e na proposta curricular uma estrutura institucional responsável por manter a violência simbólica e estrutural, e em algumas vezes, inclusive, física e sexual, como no caso dos trotes ${ }^{8,9}$. Essa instalação era um convite para que pudéssemos expor essas injustiças, que buscam silenciar as vítimas, e avançar no debate sobre os determinantes em saúde, como o machismo, o sexismo, o racismo, a LGBTIfobia e outras violências, ao longo da formação médica ${ }^{8}$. A programação do evento previa mesas com debates sobre essas temáticas, como "Saúde no combate às opressões: identidade de gênero e orientação sexual”, "Opressão institucional e violência no âmbito universitário", "Acessibilidade: como incluir o aluno com necessidades especiais?" e o fórum "Saúde de populações negligenciadas".

No ano seguinte, o $54^{\circ}$ Cobem, realizado em Brasília, ampliava o debate com a temática "Ensinar e aprender Medicina: desafios do presente e expectativas do futuro". O evento oportunizava, novamente, debates sobre LGBTIfobia, e, por exemplo, estudantes transgêneros foram convidados a falar sobre suas experiências ao longo de sua formação. Outra atividade foi o painel sobre "A cor do curso de medicina", com a coordenação do Coletivo Negrex, em que se discutiu a pequena presença de negras e negros nos cursos médicos e o acesso ao ensino superior e a permanência nele. A mesa "Mulheres na Medicina e Sociedade" abordou a presença das mulheres no mercado de trabalho e luta pela emancipação nas escolas médicas9.

Em 2017, o $55^{\circ}$ Cobem, realizado em Porto Alegre, tinha como tema "Formação médica: educação, política e atenção à saúde". Diante da ampliação formal da programação do congresso com a temática das diversidades - aqui compreendidas a partir do debate das DCN1 -, um grupo de educandos(as) e educadores(as) se reuniu para pensar como as questões de gênero e sexualidade poderiam ser ampliadas 
ao longo da formação médica. Ao final do evento, em assembleia geral, esse grupo apresentou a "Carta LGBT" ou "Carta de Porto Alegre", que defendia a equidade de gênero e da diversidade sexual na educação médica ${ }^{10}$. Esse documento propunha competências profissionais a serem adquiridas na graduação e recomendações para a organização das atividades curriculares relacionadas à saúde LGBTI+. A "Carta de Porto Alegre", além de se orientar por diretrizes da (OMS)" e outras nacionais, considerava a própria vivência de alguns autores, como estudantes, professores(a) ou preceptores(as), como pessoas LGBTI+ na escola médica. Ampliava-se cada vez mais o debate de gênero e sexualidade na formação em saúde.

O $56^{\circ}$ Cobem, realizado em Vitória, tinha como tema "Desenvolvimento docente" e apresentou, em uma de suas mesas redondas, a discussão "Competência docente: lidar com a diversidade e evitar o preconceito". Os subtemas dessa atividade traziam reflexões a respeito do preconceito, dos assédios moral e psicológico, das acessibilidades física e pedagógica, dos marcos legais e da cidadania, e da importância dos coletivos. Uma das atividades de "Como Eu Faço", na qual os congressistas deveriam apresentar experiências exitosas de suas localidades, abordou o tema "Atendimento de populações marginalizadas em parceria com o Consultório na Rua de Campinas".

Em 2019, $057^{\circ}$ Cobem, realizado em Belém do Pará, propunha o debate "Educação médica transformadora: compromisso e responsabilidade social". Diante desse convite para repensarmos "como" estávamos efetivando o compromisso e a responsabilidade social na formação médica, várias atividades debateram sobre as questões da DSPSD. A miniconferência "Como estamos acolhendo e ensinando medicina ao estudantes indígenas?" ofereceu a oportunidade para que estudantes indígenas compartilhassem suas vivências. Especificamente, durante a mesa-redonda "Como temos enfrentado as questões relacionadas à população LGBTI no ensino médico?", identificou-se a necessidade de promover maior visibilidade à temática da sexualidade e da diversidade nos eventos da Abem e nos currículos médicos. Foi aí que o grupo de trabalho Populações (In)Visibilizadas e Diversidades (GT-PIVD) da Abem teve o seu início.

\section{RELATO DE EXPERIÊNCIA}

\section{O grupo de trabalho}

Após os primeiros encontros com membros da diretoria da Abem, compreendeu-se que essa proposta poderia estar vinculada ao eixo "Inclusão e Permanência" do Projeto Abem "Saúde e Bem-Estar de Educandos e Educadores". Encaminhouse a proposta do GT-PIVD ao Conselho de Administração da Abem e, logo após, para aprovação em reuniões das regionais da associação.
Depois dos primeiros encontros presenciais, que ocorreram ainda durante o Cobem, e posteriormente à distância, entendeu-se que o foco principal do GT é promover visibilidade e articular ações (pesquisa, ensino e extensão universitária) com a Abem e os espaços de educação médica sobre os temas de gênero, sexualidade, raça, etnia, na perspectiva da DSPSD, e suas interseccionalidades. Verificouse a necessidade de aprofundar, ao longo dos eventos de educação médica e da formação de graduação, o debate sobre populações negligenciadas e invisibilizadas socialmente, como LGBTI+, negra, indígena, privada de liberdade, ribeirinha, rural, cigana, imigrantes, refugiados humanitários e pessoas com necessidades especiais; além de buscar aproximação com movimentos sociais e identitários. Mesmo diante da ausência de educandas/os e educadoras/es que trabalham com alguns desses assuntos, consideramos importante estarem discriminados a fim de sensibilizar pessoas a compor o GT, podendo, inclusive, ampliar essas questões.

A fim de iniciar os trabalhos com os presentes no $57^{\circ}$ Cobem, propôs-se uma organização por eixos temáticos, os quais poderiam ser ampliados e modificados ao longo do processo. Como critérios para proposição do eixo, consideraramse possíveis representações identitárias, áreas de expertise e atuação das pessoas presentes, tentando incluir pelo menos um(a) educando(a) e um(a) educador(a) em cada um dos seguintes eixos: gênero e sexualidade; população negra; povos indígenas; pessoas privadas de liberdade; população ribeirinha.

Para aprimorar o diálogo e as ações do GT, propôs-se a construção de uma comunidade de práticas em um aplicativo de mensagens de celular (WhatsApp). Destaca-se que essa concepção dialoga com a proposta de construção de uma rede de educandos(as) e educadores(as) presente na seção III - “Da Educação em Saúde" - das próprias DCN1. Ademais, essa comunidade é aberta a todos(as) os(as) interessados(os) em debater o tema do GT. Segundo Wenger-Trayner e WengerTrayner12: "Comunidades de prática são grupos de pessoas que compartilham uma preocupação ou uma paixão por algo que fazem e aprendem como fazê-lo melhor à medida que elas interagem regularmente".

A partir disso, buscou-se compreender o perfil dos(as) integrantes dessa comunidade de práticas a fim de aprimorar as ações e proposições do GT com a Abem e suas regionais. Para isso, realizou-se um cadastro eletrônico voluntário que continha informações sobre o estado em que o(a) integrante reside, a instituição em que estuda/trabalha, o cargo/a função na instituição, a associação ou não à Abem, a raça/ etnia, a identidade de gênero, a orientação afetivo-sexual, os trabalhos feitos e/ou o interesse de realizar um em relação às temáticas do GT, entre outros. 
À época do cadastro, a comunidade de práticas contava com 115 participantes, dos quais 74 realizaram o cadastro até o dia 12 de dezembro de 2019. Em relação ao estado em que cada participante mora, há uma representatividade de todas as regiões brasileiras, com predomínio do Sudeste, principalmente dos estados de Minas Gerais, Rio de Janeiro e São Paulo. Em relação ao cargo ou à função que desempenha na instituição em que estuda/trabalha, observa-se um grupo bastante heterogêneo, com predomínio de educandos(as) (discentes) e educadores(as) docentes e preceptores(as), respectivamente.

Dos associados(as) membros, 48,6\% são filiados(as) à Abem e 51,4\% não. Em relação à raça/etnia, há um predomínio da autodeclaração da cor branca, seguida pardos(as) e pretos(as). Quanto à identidade de gênero, há uma maior proporção mulheres cisgênero, seguidas por homem cis. No que concerne à orientação afetivo-sexual, há um predomínio de homossexuais/gays/lésbicas, seguidos por heterossexuais e bissexuais/pansexuais.

Em relação ao desenvolvimento de ações de pesquisa, ensino e/ou extensão universitária, observa-se que 54,1\% dos(as) participantes já realizam alguma ação em suas instituições, como componentes curriculares obrigatórios e optativos, atividades de pesquisa e extensão, entre outras. Quando questionados(as) em qual(is) eixo(s) do GT os(as) integrantes dessa comunidade de prática gostariam de participar, observa-se um predomínio do interesse em relação às questões de gênero e sexualidade, da população negra e dos povos indígenas, respectivamente.

\section{DISCUSSÃO}

A DSPSD está em discussão desde o movimento de reforma sanitária no Brasil. Entretanto, a incorporação desse debate nos processos organizativos da educação médica nacional ocorreu de forma mais intensa nas DCN de 2014, com a recomendação de que os processos formativos em saúde deveriam considerá-lo nas ações de cuidado individual e coletivo, bem como nos processos de gestão e educação em saúde. Vale ressaltar que a Abem, desde a sua primeira reunião em 1963, já apontava para a importância de uma educação médica que fosse além dos aspectos biológicos ${ }^{13}$. Gilberto Freyre, na conferência inaugural dessa reunião, destacava a necessidade de articulação de vários campos do saber para a formação médica, como a Sociologia:

Nem a Medicina nem a Sociologia podem dar-se ao luxo de se extremarem em especialismos sem perderem a sua sanidade ou sua autenticidade: ambas, tendo que lidar com o Homem social, precisam de lidar com o Homem social total, antes de considerá-lo apenas e estreitamente neste ou naquele particular: coração, fígado, cérebro, olhos, nariz, garganta, ouvido, nervos, uretra, órgãos genitais, pelo médico; economia, arte, educação, política, sexo, classe, idade, religião, pelo sociólogo [...]. Ao médico moderno, como ao moderno sociólogo, é necessário que junte à sua ciência aquela "visão social" [... $]^{13}$ (p. 31).

Essa "visão social" está relacionada com a responsabilidade e o compromisso social que as instituições de ensino precisam ter. $\mathrm{E}$ a Abem, desde o início, sempre se revestiu dessa missão que as DCN de 2014 também incorporaram. Ressalta-se que a responsabilidade social é um compromisso a ser promovido por todas as instituições de ensino e cuidado em saúde. Para que isso realmente ocorra e consigamos responder às reais necessidades em saúde da população, os projetos pedagógicos dos cursos devem incorporá-la. Entretanto, observa-se que a educação médica ainda é marcada pelos reducionismos biologicistas, com hipervalorização dos aspectos técnicos em detrimento dos demais ${ }^{14}$.

Uma estratégia possível para lidar com essas questões e ampliar os processos de ensino e cuidado em saúde é por meio da construção de parcerias e redes. As DCN1 apontam, no item VI do artigo $6^{\circ}$, a importância do desenvolvimento de parcerias e construções de redes, na perspectiva de aproximar instituições, serviços, educandos(as) e educadores(as) para a promoção do cuidado integral em saúde. Além disso, o item VI do artigo $7^{\circ}$ afirma que essas redes têm a possibilidade de ampliar a corresponsabilização com o cuidado à medida que há a identificação de novos desafios para o ensino e a promoção da saúde 1 .

Com isso, o GT-PIVD da Abem reúne um coletivo de educandos(as) e educadores(as) com a responsabilidade e o compromisso de promover o debate da DSPSD ao longo da formação médica e também articular ações para a promoção dos direitos humanos e da diversidade, com redução das iniquidades em saúde. Quando se procuraram - na rede de educando(as) e educadores(as) nacionais e internacionais, bem como na literatura indexada sobre o tema - relatos e/ ou análises que descrevessem experiências semelhantes, identificou-se que a Associação Australiana de Estudantes de Medicina (Australian Medical Students' Association - AMSA) tem uma ação semelhante ao GT, uma vez que, ao trabalhar o conceito de determinantes sociais em saúde, ela desenvolveu um documento que aborda a situação geral de saúde de seus povos originários, como população aborígene e população nativa das Ilhas Torres Strait, contendo orientações de conduta para profissionais e estudantes da saúde ${ }^{15}$.

Além disso, a entidade Representativa dos Estudantes de Medicina da Alemanha (Bundesvertretung der Medizinstudierenden in Deutschland e.V. - BVMD), por sua vez, 
possui o programa Estudantes de Medicina para Refugiados (MSFR). Em seu material, relata iniciativas estudantis que promovem melhorias no cuidado médico dessas populações, como a inserção de intérpretes nas consultas médicas e a adoção de formulários de anamnese bilíngues ${ }^{16}$. quando se fez essa busca, dois aspectos se fizeram patentes. $O$ primeiro consiste no pioneirismo brasileiro em debater o conjunto das populações invisibilizadas de forma integrada. $O$ segundo diz respeito ao forte engajamento estudantil em pautar essas temáticas em todo o globo, com diferentes níveis de aprofundamento. No Brasil, a Direção Executiva Nacional dos Estudantes de Medicina (Denem) tem, historicamente, trazido a educação médica como uma de suas pautas visando promover uma proposta pedagógica emancipatória e capaz de formar médicos aptos a transformar a realidade ${ }^{17}$. A proposta desse GT dialoga com essa visão por compreendermos que a universidade cumpre seu papel social ao voltar seus olhares para esses grupos sociais. Pode-se notar, diante disso, o pioneirismo dessa iniciativa nos âmbitos nacional e internacional.

Como uma rede, uma comunidade de práticas ${ }^{12}$, esse GT tem promovido trocas de experiências e aprendizagem sobre as populações (in)visibilizadas e diversidades. Segundo Cruess, Cruess e Steinert ${ }^{18}$, comunidades de práticas têm uma ampla e robusta capacidade de promover a aprendizagem, abrangendo os aspectos multifacetados da medicina, incluindo seus fundamentos teórico-práticos, como a promoção de uma identidade profissional mais engajada com a problemática da sociedade. Isso pode ser observado pelas trocas de atividades que ocorreram no GT, bem como suas produções, como o editorial da Revista Brasileira de Educação Médica intitulado "Posicionamento do Grupo de Trabalho Populações (In) Visibilizadas e Diversidades a Respeito das Violências contra a População Negra e do Racismo Estrutural" "', em apoio às ações antirracistas que efervesceram em 2020 por causa da exacerbação de práticas violentas contra a população negra durante a pandemia da Covid-19, reafirmando o compromisso com uma educação médica integral e livre de preconceitos.

Ressalta-se que, neste momento de pandemia, o GT potencializou o compartilhamento de eventos e textos sobre o cuidado em saúde às populações vulnerabilizadas no contexto da Covid-19. Esse aspecto permitiu o aprimoramento de ações formativas e assistenciais em saúde de forma mais efetiva às reais necessidades em saúde dessas populações. Esse aspecto exemplifica a potencialidade das comunidades de práticas como promotoras de profissionais com uma maior expertise, termo compreendido como um produto dinâmico da comunidade e não como uma propriedade que é "transmitida" de professor a aluno, além de promover a sensação de pertencimento ${ }^{12,18}$.
Isso foi observado no GT desde a sua fundação, uma vez que muitos dos(as) integrantes são membros de populações invisibilizadas e/ou pesquisadores(as) da área que acabam relatando vivências de exclusão ao longo do ensino e cuidado em saúde, especificamente na Medicina. Roberts ${ }^{19}$ problematiza o pertencimento ao longo da medicina a partir do fato de que a escola médica, como instituição social, estabelece fronteiras por meio de suas normas, seus valores e poderes hierárquicos socioeconômica e culturalmente construídos. Assim, a sensação de inclusão ou exclusão é frequentemente relatada ao longo da graduação, e a experiência de ser aceito, incluído e valorizado pelos outros é considerada importante.

Forrester ${ }^{20}$, médica afro-caribenha e professora da escola de Medicina da Maryland University de Baltimore, nos Estados Unidos, problematiza essa questão a partir de seu relato sobre os motivos que a fizeram permanecer na Faculdade em Medicina, enquanto outros(as) abandonaram o curso por se sentirem invisibilizados(as), vulnerabilizados(as), excluídos(as), subjugados(as) e violentados(as). Em relação aos motivos que colocam um(a) outro(a) em uma posição excludente e menosprezada, o GT, como uma comunidade de práticas, busca promover a diversidade e os direitos humanos, e ampliar a sensação de pertencimento, reduzindo o isolamento.

Sobre os motivos que levaram Forrester ${ }^{20}$ a permanecer no curso, destacamos dois: a representatividade e o ser agente de mudanças. Em relação à representatividade, a autora reitera que a presença de corpos historicamente excluídos potencializa a vocalização de outras vozes historicamente silenciadas. E o ser agente de mudanças está relacionado com proposições de aprimoramentos nos espaços de ensino e cuidado em saúde em relação à diversidade e aos direitos humanos $^{20}$. Nesse sentido, o GT traz consigo esse papel de promover a representatividade nas diferentes escolas médicas, bem como dentro da própria Abem. Ademais, o protagonismo de educandos(as) e educadores(as) no GT potencializa o papel de agentes de mudanças nos vários espaços e contextos em que estão inseridos. O GT reitera seu compromisso com as DCN1 ao potencializar o processo de ensino-aprendizagem e cuidado em saúde crítico, reflexivo, humanista e ético.

\section{CONCLUSÕES}

Apesar de vigentes há mais de seis anos, as DCN seguem sendo questionadas por parte da comunidade acadêmica e por órgãos do Estado desde sua promulgação. Ainda que eventualmente requeiram pequenos ajustes, constituem inegavelmente um avanço em vários aspectos, principalmente em relação à cidadania e à responsabilidade social. Os diferentes organismos nacionais e internacionais que adotam recomendações de prática de uma medicina e de um ensino 
médico mais próximos da necessidade das pessoas e das coletividades, em especial daquelas mais vulneráveis ou menos reconhecidas, reforçam o acerto das DCN brasileiras. A sua incipiente implementação no conjunto das escolas impõe um desafio à Abem e a todos os grupos interessados em práticas médicas e de ensino que dialoguem com o contexto real de nosso país. O grupo encontrou, na criação desse coletivo na Abem, um marco importante da luta por esse objetivo, que adicionalmente reforça o SUS a partir da compreensão dele como ordenador da formação em saúde e como o cenário capaz de visibilizar essas necessidades e propor caminhos para o seu enfrentamento. O surgimento desse GT reforça o compromisso da Abem de promover o desenvolvimento da educação médica no país, visando à formação de médicos capazes de atender às necessidades de saúde da população, contribuindo para o fortalecimento do SUS e a construção de uma sociedade mais justa e igualitária.

\section{AGRADECIMENTOS}

Agradecemos a todos(as) os(as) integrantes do GT Populações (In)Visibilizadas e Diversidades, ao conselho diretor da Associação Brasileira de Educação Médica e ao GT Gênero, Sexualidade, Diversidade e Direitos da Sociedade Brasileira de Medicina de Família e Comunidade. Agradecemos também a todas as pessoas que de alguma forma contribuíram para a construção dessa história.

\section{CONTRIBUIÇÃO DOS AUTORES}

Todos(as) os(as) autores(as) contribuíram igualmente na construção do artigo.

\section{CONFLITO DE INTERESSES}

Os(as) autores(as) declaram não haver conflito de interesses neste estudo.

\section{REFERÊNCIAS}

1. Brasil. Diretrizes Curriculares Nacionais do Curso de Graduação em Medicina. Brasília: Ministério da Educação; 2014.

2. The Net. Global Consensus for Social Accountability of Medical Schools. Vancouver; 2010. Acesso em: 5 set 2020. Disponível em: http:// healthsocialaccountability.sites.olt.ubc.ca/files/2011/06/11-06-07-GCSAEnglish-pdf-style.pdf.
3. Division of Development of Human Resources for Health, World Health Organization. Defining and Measuring the Social Accountability of Medical Schools. Geneva: World Health Organization; 1995. Disponível em: http://whqlibdoc.who.int/hq/1995/WHO_HRH_95.7.pdf.

4. Brasil. Constituição da República Federativa do Brasil. Brasília: Senado Federal; 1988.

5. Brasil. Ministério da Saúde. Lei $n^{\circ}$ 8.080, de 19 de setembro de 1990. Dispõe sobre as condições para a promoção, proteção e recuperação da saúde, a organização e o funcionamento dos serviços correspondentes e dá outras providências. Diário Oficial da União; 1990;1-13. Acesso: 5 set 2020. Disponível em: www.cff.org.br/userfiles/file/leis/8080.pdf.

6. De Albuquerque GSC, e Silva MJS. Sobre a saúde, os determinantes da saúde e a determinação social da saúde. Saude em Debate. 2014;38(103):953-65.

7. De Oliveira SS, Postal EA, Afonso DH. As escolas médicas e os desafios da formação médica diante da epidemia brasileira da COVID-19: das (in) certezas acadêmicas ao compromisso social. APS em Rev. 2020;2(1):56-60.

8. Sharma $M$, Pinto $A D$, Kumagai AK. Teaching the social determinants of health: a path to equity or a road to nowhere? Acad Med 2018;93(1):25-30.

9. Raimondi GA. Corpos que (não) importam na prática médica: uma autoetnografia performática sobre o corpo gay na escola médica [tese]. Campinas: Universidade Estadual de Campinas; 2019.

10. De Melo LP, dos Santos GBS, Raimondi GA, Paulino DB, de Almeida MM, de Barros EF, et al. Carta de Porto Alegre: em defesa da equidade de gênero e da diversidade sexual na educação médica. Porto Alegre; 14 out 2017. Acesso em: 5 set 2020. Disponível em: https://website.abemeducmed.org.br/wp-content/uploads/2019/09/CARTA-LGBT-1-1.pdf.

11. Department of Gender, Women and Health, World Health Organization. Integrating gender into the curricula for health professionals: meeting report. 4-6 December 2006. Department of Gender. Geneva: World Health Organization; 2007.

12. Wenger-Trayner E, Wenger-Trayner B. Introduction to communities of practice: a brief overview of the concept and its uses. 2015 [site]. Acesso em: 5 set 2020. Disponível em: https://wenger-trayner.com/wp-content/ uploads/2015/04/07-Brief-introduction-to-communities-of-practice.pdf.

13. Associação Brasileira de Educação Médica. I Reunião Anual: Novos rumos para o ensino médico no Brasil. Belo Horizonte: Abem; 1963.

14. Barros NF. As ciências sociais na educação médica. São Paulo: Hucitec; 2016.

15. Spurling G, Felton-Busch C, Larkins S. Aboriginal and Torres Strait Islander health. Aust J Prim Health. 2018;24(5):i-ii.

16. Der AGF. Projektskizze für Kooperationsprojekte - Optional vor der Antragstellung [site]. Acesso em 5 set 2020. Disponível em: www.zim. de/ZIM/Redaktion/DE/Downloads/Formularcenter/A_Phase-Antrag/B Kooperationsprojekt/B1_Ohne-Netzwerk/projektskizzē.html.

17. Raimondi GA, de Souza LP, Moraes VHA, Afonso DH, Borret RHES, Tourinho FSV, et al. Posicionamento do Grupo de Trabalho Populações (In) Visibilizadas e Diversidades a Respeito das Violências contra a População Negra e do Racismo Estrutural. Rev Bras Educ Med. 2020;44(3):e093.

18. Cruess RL, Cruess SR, Steinert Y. Medicine as a community of practice: implications for medical education. Acad Med. 2018;93(2):185-91.

19. Roberts LW. Belonging, respectful inclusion, and diversity in medical education. Acad Med. 2020;95(5):661-4.

20. Forrester A. Why I stay - the other side of underrepresentation in academia. N Engl J Med. 2020;383(4):e24. 